\title{
Review of national social protection strategies
}

\author{
Anna Orrnert \\ Future Seed CIC \\ 3 February 2020
}

\section{Question}

Please provide a review of national social protection strategies, mapping their content, scope and timeframes, the processes used to develop them and proposed indicators to measure their success. Please identify key similarities and differences across strategies and highlight examples of good practice.

\section{Contents}
1. Summary
2. National Social Protection Strategy development process
3. Content
4. Implementation tools
5. Good practice
6. References

\footnotetext{
The K4D helpdesk service provides brief summaries of current research, evidence, and lessons learned. Helpdesk reports are not rigorous or systematic reviews; they are intended to provide an introduction to the most important evidence related to a research question. They draw on a rapid deskbased review of published literature and consultation with subject specialists.

Helpdesk reports are commissioned by the UK Foreign, Commonwealth, and Development Office and other Government departments, but the views and opinions expressed do not necessarily reflect those of FCDO, the UK Government, K4D or any other contributing organisation. For further information, please contact helpdesk@k4d.info.
} 


\section{Summary}

This helpdesk report reviews ten national social protection strategies (published between 20112019 ) in order to map their content, scope, development processes and measures of success. Each strategy was strongly shaped by its local context (e.g. how social development was defined, development priorities and existing capacity and resources) but there were also many observed similarities (e.g. shared values, visions for social protection).

The search focused on identifying strategies with a strong social assistance remit from the Middle East and North Africa (MENA), Sub-Sarahan African and South and South-East Asian regions ${ }^{1}$ (Latin America was deemed out of scope due the advanced nature of social protection there). Examples from Sub-Saharan Africa are most widely available. Few examples are available from the MENA region ${ }^{2}$ - it may be that such strategies do not currently exist, that potential strategy development process are in more nascent stages or that those strategies that do exist are not accessible in English. A limitation of this review is that it has not been able to review strategies in other languages. Saudi Arabia, for example, has developed a National Social Development Strategy (NSDS) which focuses on a range of social issues, including social protection (Said Alsayyad 2017: 65) - however only secondary sources about this strategy have been identified.

The strategies reviewed in this report are from Bangladesh (2015), Cambodia (2011), Ethiopia (2012), Jordan (2019), Kenya (2011), Lesotho (2014), Liberia (2013), Rwanda (2011), Uganda (2015) and Zambia (2014). The content of this report focuses primarily on the information from these strategies. Where appropriate, it also includes information from secondary sources about other strategies where those original strategies could not be found (e.g. Saudi Arabia's NSDS).

Pino and Badini Confalonieri's (2014) comparative analysis of national social protection policies in West Africa usefully identifies seven distinct stages that countries usually go through in the development of their national social protection policies: defining a national vision, defining social protection, identifying guiding principles, key areas and mechanisms for implementing and financing their national social protection policies. The strategies reviewed here reflected this approach.

Developing a national social protection strategy is often a long-term process, which can take several years. The amount of time varies between countries. For example, the process took 8 months in Rwanda, but several years in Kenya. The processes are most often coordinated by one government ministry (with some sort of social protection remit) and involve a range of actors (from across different ministries, international donor partners and civil society organisations as well as businesses and employers, and representatives from organisations working with vulnerable groups).

\footnotetext{
${ }^{1}$ Malaysia began the process of developing a National Social Protection Strategy in 2019 (Malay Mail 2019). It was not possible to identify detailed information about this. Villar (2013) provides an overview of the process in the Philippines, although it was not possible to access the original strategy document.

2 Some insights can be found in ESCWA (2019: 82-86), although detailed information on National Social Protection Strategies (NSPS) is not available. It states for example, that Mauritania began the process of developing a NSPS in 2013.
} 
The content of strategies included many similarities:

- Most strategies articulate an explicit vision of social protection, as well as guiding principles to undertake the work. These are linked closely to national values, existing development and poverty reduction priorities, national legislation and/ or international commitments.

- Strategies distinguished between long- and short-term goals and objectives. In the shortterm, these relate to providing support for the poor and vulnerable; in the longer-term, they aim for a gradual expansion of other social protection interventions.

- There is no universal definition of social protection across contexts, although many shared common characteristics, such as focusing on protecting the poorest and most vulnerable.

- Social protection interventions in different contexts can include both public and private interventions as well as formal and informal mechanisms.

- Some definitions also included policies or legislative measures.

- In operational terms, social protection in most strategies refers either to social assistance (social safety nets) or social insurance (social security schemes to protect against risks).

- Strategies also identify implementation mechanisms. In most cases, these include institutional frameworks (coordination mechanisms and roles and responsibilities of key stakeholders), financing arrangements and plans for monitoring and evaluating both individual social protection programmes and overall strategies. More detailed implementation plans are also produced as separate documents to guide the strategy to implementation.

A number of good practices were identified from the strategies and wider literature. For example, developing a viable long-term financing strategy is necessary to ensure the sustainability of national social protection strategy development and implementation.

\section{National Social Protection Strategy development process}

Not all the social protection strategies reviewed include information about how the strategies were developed (for example, the Ethiopia and Lesotho strategies do not). However, those that do suggest that the process most often involves government-led consultation with a range of partners, including various government ministries, international development partners and civil society organisations.

Different governmental actors led the process in different countries:

- In Rwanda, the process was led by the Ministry of Local Government.

- In Bangladesh the process was jointly led by the General Economics Division (GED) of the Planning Commission.

- Similarly in Liberia, the Ministry of Planning and Economic Affairs led the process, although UNICEF also took on a leadership and oversight role in the process.

- In Jordan the process was co-chaired by the Minister of Planning and Development Cooperation and the Minister of Social Development. 
- In Cambodia, coordination of the strategy development process was led by The Council for Agricultural and Rural Development (CARD)

- In some cases, donor organisations also took on leadership and oversight role (for example, UNICEF in Liberia).

Most often, the coordinating ministry set up cross-governmental steering groups or working groups (primarily comprising a range of government ministries, often with a social protection or social development mandate) which carried out consultations and meetings with the other stakeholders, including various government ministries, international donors and local civil society organisations. In some cases, consultations involved other actors:

- In Liberia, consultation involved county representatives, beneficiaries from a pilot cash transfer programme as well as children from the Children's Parliament (Liberia, 2014: 3).

- In Kenya, consultation included actors from the private sector (Kenya, 2011: 1).

- Unspecified parastatal actors were involved in the Rwandan process.

- In Uganda, the process incorporated faith-based organisations and "traditional and cultural institutions" (Uganda, 2015: iv).

- In Jordan, where social protection has historically included zakat mechanisms (Jordan 2019: 8), meeting(s) were also held with the Minister of Islamic Affairs and Holy Sites and consultations included participants from Zakat Fund ${ }^{3}$.

Technical and financial support for these consultations was often provided by international donors (e.g. Jordan, Liberia, Ghana and Kenya). In Zambia, the Government of Finland cofinanced the process of formulating the policy (Zambia, 2014: 4).

As highlighted by a number of the strategies reviewed, the development and implementation of a national social protection strategy is a long-term process. The initial draft is often developed as part of a pilot project, involving several additional stages of strategy development and implementation. Whilst a few of the strategies were developed in less than a year, most took longer:

- Cambodia's process provides an example of these stages, illustrating how long the process of developing a national social protection strategy can take (Cambodia, 2011: 9):

- 2009-2011: Strategy formulation and adoption by the Council of Ministers

- 2011-2013: Implementation of short-term priority action plan

- 2013: Mid-term review and adjustment/update of implementation plan

- 2014-2015: Implementation of updated implementation plan

- 2015: Evaluation and updating/revision of National Social Protection Strategy

The 2011 strategy states that the "transparent and rigorous consultation process has ensured that the analytical and policy inputs have gone through several rounds of

\footnotetext{
${ }^{33}$ The Zakat Fund is another critical institution that provides assistance to the poor. Operated as a government institution under the Ministry of Awqaf, local Zakat committees collect private donations and provide assistance to beneficiaries within the same geographic area. Zakat Committees have established highly successful communitylevel facilities and programs. The Zakat Fund also provides cash transfers, primarily targeted to households hosting orphans. (Jordan 2019: 3)
} 
discussion and are the result of a combined effort by all stakeholders" (Cambodia, 2011: 7).

- The implementation of Saudi Arabia's National Social Development Strategy (although not covered in detail in this review) will take 26 years. Implementation was designed in three separate stages, between 2004 - 2030 (Said Alsayyad 2017: 65-66).

- Uganda has also gone through several stages in its development of its National Social Protection Policy. The first draft took five years to develop and was published in 2015, alongside a Programme Plan of Interventions. A second version of the strategy is currently under development.

- In Rwanda, despite involving a range of actors (e.g. Vice-Mayors in charge of Social Affairs and Economic Development, Local Government officials, NGO representatives and Civil Society representatives from all Districts in all provinces and Kigali City) and a number of additional events (including validation workshop, inter-ministerial consultations and a technical committee on NSPS) the initial strategy development process took place over 8 months. However, Rwanda defines its long-term vision for social protection as covering 10 years.

- Bangladesh's National Social Security Strategy sets out the implementation period for implementing the strategy in two phases of five years each (2016 - 2021 and 2021 2025) (Cabinet Division and General Economics Division of Planning Commission 2016 : ii).

- Kenya began its strategy development process in 2006, holding a series of national consultation meetings with government ministries and non-state actors, as well as exploring international best practices in the provision and financing of social protection. The final strategy was published in 2011.

- Liberia's strategy development process took more than a year, as a result of consultations with a range of stakeholders, intended to represent "the collective thinking of all stakeholders in Liberia" (Liberia, 2013: 8).

- In Jordan, 18 different workshops were held with a large number of stakeholders, although limited detail is provided on the content of these workshops ${ }^{4}$ (see Jordan, 2019: for a full list of participants in the process), and the strategy does not specify how long this process took.

\section{Content}

\section{Vision $^{5}$}

In their review of national protection policies in West Africa, Pino and Confalonieri (2014) identify defining a national vision as the first stage in developing a national social protection strategy/ policy. According to Pino and Confalonieri, a national vision "describes what a country wishes to become, the national priorities and the objectives to be reached (Pino and Confalonieri 2014: 132). Of the national strategies reviewed here, most articulated an explicit vision for their social

\footnotetext{
${ }^{4}$ The strategy document only states that the workshops discussed "the relevant sectors, programs and policies".

${ }^{5}$ See Appendix A for a list of the visions articulated in each individual national social protection strategy.
} 
protection. Similarly, to Pino and Confalonieri's (2014: 132) findings, these visions are linked to wider national development and poverty reduction strategies, articulating development in both social and economic terms. They note that social protection is key to achieving economic growth and social and human development.

Visions articulated, first and foremost, social protection for the most vulnerable, while aiming for eventual progressive expansion of the social protection system. Bangladesh's strategy states that its vision "while being rooted in a rights-based approach, a Social Protection Floor [...] will initially have to prioritise in consideration of its institutional capacity, fiscal space, inertia of existing system and administrative structures and the most urgent social and economic needs." Therefore, during initial years of implementation, "emphasis will be given to hard-core poor and the most vulnerable sections of the population" (Bangladesh, 2015: ix)

Many strategies emphasise the need for long-term vision for developing social protection systems. For example, Bangladesh sets out steps for the next 5 years in order to achieve its vision "while being cognizant of the reality that substantial change will take time" (Bangladesh, 2015: 47-48). Similarly, Liberia's Vision is set out over 17 years since "comprehensive and sustainable social protection systems cannot be built in the short-term." (Liberia, 2013: 45). Many visions focused on inclusivity. For example, Cambodia's vision aims "to ensure a basic guarantee of social protection for the entire population" (Cambodia, 2011,47), while

Bangladesh's vision articulates a long-term vision of a social security system that is available to "all the people of Bangladesh who are in need of support" (Bangladesh, 2015: 48). Interestingly, in another section this seems to be qualified by stating that this inclusive social security system is "for all deserving Bangladeshis" (though it does not explain what constitutes deserving) (Bangladesh, 2015 xxi).

\section{Defining social protection ${ }^{6}$}

The strategies reviewed reveal that there is no universal definition of social protection across contexts, although many definitions share common characteristics. Most focus on interventions to protect the poorest and most vulnerable, particularly against financial/ economic consequences of risk or shocks:

- Ethiopia and Zambia both base their definition on the African Union Social Policy Framework (AU-SPF) which emphasises the need for social protection to support development, building human capital, breaking of the intergenerational poverty cycle and reduction of inequalities.

- Uganda sums up its definition of social protection as 'a basic service and a human right that ensures dignity of people' (Uganda, 2015: 1).

- Bangladesh's Strategy also sets out the vision of moving towards a rights-based approach to delivering social protection.

- Rwanda's definition includes reducing the vulnerability of marginalised groups by enhancing their social status and rights. In addition to enhancing capacity and opportunities for the poor and vulnerable,

\footnotetext{
${ }^{6}$ See Appendix B for more detailed definitions of social protection used in each national social protection strategy.
} 
- Kenya's definition includes actions that 'enable income-earners and their dependants to maintain a reasonable level of income through decent work, and that ensure access to affordable healthcare, social security, and social assistance' (Kenya, 2011:2).

- Although the Jordanian strategy does not explicitly define social protection, it refers to social protection more broadly, as "programmes designed to support its citizens to meet their basic needs and to deal with poverty-related risks" (Jordan, 2019: 8).

- Some definitions emphasise primarily public interventions (e.g. Liberia) while others (Rwanda, Uganda) include both public and private interventions.

- Some strategies (e.g. Cambodia, Ethiopia, Uganda) included both formal and informal mechanisms in their definition.

- Alongside the more formal social protection schemes, the Ugandan strategy also includes informal and traditional social protection mechanisms embedded in communities (e.g. family and clan support systems, mutual assistance schemes and neighbourhood support groups), noting that these have "played a significant role in assisting individuals and families during times of need and distress" (Uganda, 2015: 2).

In addition to interventions, programmes, actions and instruments, some definitions also included policies (e.g. Liberia, Kenya, Zambia) or legislative measures (e.g. Kenya). Lesotho's strategy distinguishes between social protection 'as an objective', and social protection 'as a set of instruments'. It notes that although the objective of providing social protection might be included in a range of sectoral strategies (e.g. education, health, nutrition, security, labour markets, infrastructure and communications), the main orientation of the National Social Protection Strategy is on the specific set of instruments whose primary objective is to deliver social protection. These can be categorised as social assistance, social insurance ('social security' in Lesotho) and social care services (Lesotho, 2014: 2)

In practical terms, social protection in most strategies is made up of two key elements: social assistance (social safety nets for the poorest and most vulnerable) and social insurance (social security schemes to protect against risks, including illness, unemployment, old age etc.). This reflects the findings of Pino and Confalonieri (2014) in their review of social protection policies in west Africa. As in their study, these two elements were often supported by other components, including social services for marginalised groups, protective legislation, price subsidies and health risk coverage mechanisms. This review, however, focuses primarily on strategies with a significant social assistance component, including direct transfer programmes (cash or in kind), non-contributory schemes targeted at the poor and vulnerable.

\section{Guiding principles ${ }^{7}$}

Most of the strategies reviewed are based on a core set of guiding principles, which often reflect national priorities, values and international commitments. While these values are grounded in the local context of each country, several appear across many of the strategies:

Participation is most frequently mentioned across strategies. The principle can refer either to participation by beneficiaries in social protection programmes or to their participation in designing, planning, implementing, and monitoring programmes, or both. For example, the

\footnotetext{
${ }^{7}$ See Appendix $\mathrm{C}$ for a more detailed description of the guiding principles in each national social protection strategy.
} 
Liberian strategy states that "those individuals, households, and vulnerable groups who programs are designed to support will be consulted and involved in the design, planning and implementation of social protection interventions" (Liberia, 2013: 46-47). Some states emphasise the importance of broad participation in all stages of the strategy's development. The Ugandan strategy suggests that "communities, target groups and duty bearers shall be actively involved in the design, implementation, monitoring and evaluation of social protection interventions" (Uganda, 2015: 26), whilst Lesotho's strategy states that "beneficiaries should be consulted and closely involved in the design, planning and implementation of social protection interventions" (Lesotho, 2014: 9-10). Zambia also highlights the importance of participation "for effective service delivery, improved access and increased sustainability of social protection" (Zambia, 2014: 10)

Transparency and accountability in implementation of social protection programmes are guiding principles in several strategies. The Zambian strategy states that "accountability and transparency are crucial in social protection as they foster public confidence, acceptability and promote wider participation in programme implementation. Hence, service providers in the social protection sector must ensure the best use of available resources and account for their utilisation." Several states (e.g. Liberia, Lesotho, Kenya) also emphasise the importance of transparency in disclosure of contract terms, the need to publicise instances of abuse and transparency in targeting, eligibility and implementation. Lesotho's strategy argues that this is because "any targeting must be fair, and seen to be fair" (Lesotho, 2014: 9-10). These states also argue for effective and accessible grievance redress systems.

Sustainability is frequently mentioned. Across strategies, it emphasises different, but also related, aspects of social protection implementation, referring variously to budgetary capacities, public support and intervention results. In Liberia's strategy, sustainability refers primarily to ensuring ongoing funding: "Government and partners will be committed to reliable funding, using appropriate mechanisms that provide predictable and institutionalised funding to social protection, under Government control and sustainable over the long-term" (Liberia, 2013: 46-47). Ethiopia, on the other hand, focuses on ensuring "the state's role in social protection reflects an adequate level of public support" as well as the sustainability of interventions: "Moreover the support given to the poor shall strengthen the livelihoods of the beneficiaries and the community to lift them sustainably out of poverty by avoiding dependency and stigma" (Ethiopia, 2012: 15).

The principles of human rights and equity are often embedded in a state's Constitution, other governmental strategies or international agreements. Liberia's strategy says that "social protection will promote the progressive realisation of human rights as articulated in Liberia's constitution and other relevant national and international legal instruments and conventions" (Liberia 2013: 45). They are also sometimes linked with dignity. For example, the Zambian strategy states that "social protection service providers should respect and recognise the dignity of persons they serve in accordance with national, regional and international conventions and protocols" (Zambia, 2014: 10). In some cases, these principles are linked to other concepts. For example, Uganda states that "fairness and justice shall underpin the provision of social protection services across different demographic categories and geographical locations" (Uganda, 2015: 26). For Liberia, equity is related to access to services, and is a basic pillar of 
the Agenda for Transformation". The strategy goes on to say "social protection services have an important role to play in helping vulnerable people to secure or expand access" (Liberia 2013: 46). Zambia's strategy argues that the principle of equity "will ensure that Social Protection measures to reach the poor and vulnerable are affirmatively introduced to ensure that groups that are greatly disadvantaged are reached meaningfully to narrow the inequality gap with the rest of the population. The measures must also recognize the needs and status of different individuals such as age, gender, disability, health and socio-economic conditions" (Zambia, 2014: 10).

Other common principles include needs and evidence-based interventions; inclusivity; leadership; partnership; and gender (sensitivity/ responsiveness/ mainstreaming).

\section{Scope and objectives ${ }^{9}$}

Many of the strategies identify as their longer-term goal the establishment of a comprehensive social protection system, covering social assistance, social insurance and a range of services to support social protection. Due to resource and capacity constraints however, most recognise the need to prioritise and sequence interventions in the short-term. The more immediate focus is therefore primarily on the provision of social assistance, as well as access to basic services (e.g. education, health, shelter, water and sanitation) to the poorest and most vulnerable, with aims to progressively extend social protection provision through other types of assistance (e.g. extending contributory social protection systems, extending social security to the informal sector, health insurance, labour market interventions).

As noted earlier, however, this review focuses primarily on social assistance. For example, the Cambodian National Social Protection Strategy (NSPS) sets out its long-term vision as a comprehensive, integrated and sustainable social protection system. In the short- to mediumterm, it prioritises the development of effective and sustainable social safety nets (including conditional or non-conditional cash or in-kind transfers) targeted to the poor and vulnerable, with complementary social welfare services for special vulnerable groups (e.g. people living with HIV and orphans made vulnerable or affected by HIV). A contributory intervention of communitybased health insurance $(\mathrm{CBHI})$ targeted at the near poor who are vulnerable to falling into poverty as a result of health shocks, is also included. Alongside this, the NSPS sets the framework for sustainable and comprehensive social protection for all Cambodians over the longterm. This includes both contributory and non- contributory schemes (Cambodia, 2011: 5-6).

Rwanda also sets out its long-term plan for social protection, defining long-term as 10 years, whilst in the more immediate term prioritising interventions (including cash transfer that provide income support and access to basic services) for the poorest and most vulnerable. It aims for gradual expansion of participation of contributory social security system in the informal sector, so that more people can enjoy the benefits of labour legislation as well as social development

\footnotetext{
8 The "Agenda for Transformation" (AfT) is the Government's articulation of the new medium-term economic growth and development strategy, which seeks to catalyze the country's transition from recovery to inclusive growth.
}

${ }^{9}$ See Appendix $D$ and $E$ for more detailed descriptions of scope and objectives in each national strategy. 
initiatives and complementary activities to help the poor graduate out of poverty (Rwanda, 2011: 2-3).

The overall objectives in most strategies therefore relate in the short- to medium-term to strengthening existing social protection systems. These objectives set out measures to ensure support to the poorest and most vulnerable members of society (e.g. providing income security and building resilience against risk and shock). Additional objectives refer to progressively extending other aspects of social protection (e.g. social insurance and access to services) or helping the poor move out of poverty by building human capital (e.g. productive capacity, asset base, employment opportunities), providing support to particular vulnerable groups or enhancing the social status of marginalised people. Other objectives related to these are strengthening the institutional framework to deliver social protection (given the multi-sectoral nature of social protection), ensuring the range of stakeholders take responsibility for implementing the strategy and ensuring that social protection systems contribute to overall economic growth strategies. For example, the Liberian strategy sets the objective to develop a coherent national social protection system and ensure effective implementation of social protection programs. To do so, requires strengthening a range of structures across all levels of the Government, and putting in place new structures where gaps exist to strengthen leadership, coordination and implementation of various programs (Liberia, 2013: 13).

\section{Implementation mechanisms}

Details on proposed institutional arrangements (including clarification of roles and responsibilities and coordination of actors from across many sectors and the cross-cutting nature of social protection), financing of social protection systems and monitoring and evaluation are included in nearly all the strategies reviewed, although the level of detail provided varies. Several strategies also include information on proposed management information systems (either the development of a Single Registry as in Bangladesh or on integrating existing social protection systems). Only two strategies (Rwanda and Kenya) do not include a specific section on communications although a handful of others refer to developing a communications strategy as the responsibility of specific actors identified during the first year of the implementation phase. Additionally, Liberia includes a section on potential risks, whilst Kenya outlines policy sequencing measures.

\section{Institutional framework}

Similarities were observed in coordination arrangements. In some cases, the institutional arrangements for implementation are described in detail in the strategy. In other cases, the need for such arrangements is highlighted but contingent on additional discussions with the relevant stakeholders. This is the case in Cambodia, for example, where the body overseeing strategy development (CARD) is also tasked with ensuring that effective inter-ministerial coordination mechanisms are in place, but are not yet outlined in the strategy. More often, a specific institutional framework is outlined. Pino and Badini Confalonieri identify several specific structured approaches, which were also reflected in the strategies reviewed here: "permanent inter-ministerial structure (sometimes with a permanent secretariat), specialised technical structures and regional, sub-regional and/ or local structures' (Pino and Badini Confalonieri, 2014: 142). 
The strategies provided varying levels of detail about planned coordinating mechanisms and institutional structures (as well as roles and responsibilities of various actors) ${ }^{10}$ :

- In Ethiopia, a National Social Protection Steering Committee will be established by the Council of Ministers, tasked with meeting twice a year to review the implementation of the policy, strategies and action plans. Members will be drawn from a range of ministries, public and private social security agencies, employers and civil society (Ethiopia, 2012: 23-24).

- Kenya's strategy also sets out a National Social Protection Council (NSPC), with a membership consisting of representatives of the government ministries engaged in social protection, as well as businesses, employers, workers, social security organizations, civil society organisations and faith-based organisations. The NSPC's role is to coordinate and oversee the development, implementation, and integration of social protection strategies, programmes, and resources. Its agency will have offices at both the national and county levels. Additionally, a National Social Protection Secretariat will provide technical support and coordinate implementation of specific agenda items. Finally, County and Subcounty Social Protection Committees will be responsible for overseeing community-based interventions (Kenya, 2011: 26-28).

- In Liberia, the cross-ministerial coordinating body is chaired by The Ministry of Gender, Children and Social Protection. In addition to ministerial representatives, its membership also includes a number of multilateral and bilateral donors. This Committee is responsible for policy matters and resource mobilization and is supported by a National Social Protection Secretariat. Separate technical working groups on social assistance, social insurance, economic opportunity and economic security will also be set up to responsible for technical direction and implementing recommendations for particular programmes. These will include representatives from civil society organisations representing vulnerable groups. Administration of the social protection system will be devolved to county administration (Liberia, 2013: 64-68). Similar national and sub-national structures are outlined in many of the other strategies.

- In Bangladesh, the Cabinet Division is responsible for overseeing the National Social Security Policy and related reforms. This will be supported by relevant government ministries grouped into thematic clusters, which are designed to support cooperation between and coordination of the various implementing ministries (Bangladesh, 2015: 74-78).

- The strategies from Uganda, Lesotho and Zambia also provide detail on the roles and responsibilities of individual ministries and other actors.

\section{Measuring success}

All strategies include information on monitoring and evaluation (M\&E), although the level of detail varies considerably. Where M\&E is only briefly addressed, this may be because a separate document has been created. For example, the Jordanian strategy refers to a separate M\&E Framework document (although this was not readily accessible on the government website - it is

\footnotetext{
10 Please see ESCWA (2019: 82-86) for insights into the institutional arrangements used in some MENA countries, including in Mauritania's development of a National Social Protection Strategy which began in 2013.
} 
possible that only an Arabic version exists). M\&E is discussed in strategies with reference to both monitoring specific social protection interventions and programmes as well as the national social protection strategy itself.

Responsibility for monitoring individual programmes varies. In some cases, it is assigned to the implementing agencies, with overall oversight and coordination by the leading coordination body (Cambodia, 2011: 62-63). In Rwanda, the Social Protection Working Group monitors social protection programmes at both national and district levels (Rwanda, 2011: 55). In Kenya, impact assessments are carried out by the implementing agencies and National Social Protection Council.

Responsibility for monitoring the implementation of the national social protection strategy is often assigned to the permanent cross-ministerial group in charge of overseeing strategy development and implementation. Some strategies outline plans for ongoing monitoring throughout the implementation cycle. For example, Rwanda's strategy states that the Social Protection Working Group will monitor 6-monthly progress and that an additional joint sector review will take place annually (Rwanda, 2011: 50). In Cambodia, an annual progress report on the strategy will be based on information from implementing agencies (Cambodia, 2011: 64). The Rwandan strategy highlights that establishment of Management Information Systems will enable regular monitoring of all programmes set out in the Strategy, at all levels of government (i.e. sector, district and national) (Rwanda, 2014: 50).

Several strategies (including Jordan, Ethiopia, Liberia, Uganda, Zambia) highlight that additional evaluations will be undertaken by external actors, often halfway through and upon completion of implementation. These evaluations will examine to what extent the intended results have been achieved as well as lessons learned from strategy implementation. For example, to establish impact, gaps, emerging issues and challenges (Uganda, 2015: 40)

Few strategies provide detailed information about indicators. Bangladesh's strategy provides the most detailed look at specific indicators for monitoring programmes, policy implementation and impact. It uses a results-based approach, based on strategic, operational and learning objectives to develop specific indicators related to these objectives. Data will be collected using quantitative, qualitative and hybrid approaches (Bangladesh, 2015: 83-86). The Cambodian strategy refers to output and process indicators, with data being drawn from official statistics, administrative statistics from sector ministries, programme monitoring systems and specific surveys and assessments (Cambodia, 2011: 62-63). The Ethiopian strategy highlights monitoring of inputs and outputs, process evaluation examining efficiency and effectiveness including targeting, and impact evaluation. It suggests that a management information system will be established to aid targeting, monitoring and for auditing (Ethiopia, 2012:21). Lesotho's strategy highlights resultsbased performance indicators as well as "independent and impartial spot-checks" to verify the integrity data. Monitoring implementation of the overall social protection strategy requires the generation of indicators that allow the monitoring of financial, operational and institutional aspects of the strategy. Monitoring its impact will use both qualitative and quantitative methods to gather data on operational issues (Lesotho, 2014: 31-32).

Developing capacity for M\&E is mentioned in some strategies. For example, the Liberian strategy states that the coordinating ministry will commission an M\&E capacity assessment at all levels of government. This will inform training of staff with M\&E responsibilities in at ministry and county level and for other key partners to build capacity to implement and maintain the M\&E 
system. The development of a dedicated social protection M\&E unit within the lead ministry will also be considered (Liberia, 2013: 72).

\section{Financing}

All strategies address the financing of their strategies, with the exception of Lesotho (although a section on costs and benefits of social protection is included in this). Effective implementation of national social protection strategies depends on sufficient and predictable funding. States identify a number of different potential financing sources, depending on local context, including government revenue, international donor grants, private sector investment, civil society financing, community support, household savings and individual and employer contributions. Mix financing is the most common proposed financing method. Findings include:

- Government funding: The capacity of governments to fund social protection varies. In some cases, government funding is highlighted as the main source of social protection financing (e.g. Ethiopia, 2012: 21-22; Kenya, 2011: ix). The Ethiopian strategy proposes several ways available for the government to create fiscal space for financing social protection, including increasing economic growth, expanding tax collection as a proportion of GDP, reallocation of existing expenditure, by increasing the efficiency of existing investments and by increasing the fiscal deficit through loans, and through spending grants (Ethiopia, 2012: 21-22). The Kenyan policy proposes that the Government develop strategies to prioritise social protection financing and improve the targeting of social protection beneficiaries, reduce administrative costs, and improve fund management (Kenya, 2011: ix). Government funding is, however, often considered a longer-term option. Uganda's strategy, for example, sets out that a proportion of government revenues (to be determined through research) will support the financing of social protection services in the long-term (Uganda, 2015: 41). Where fiscal space and implementation capacity is limited, options for social protection development in the shortterm must be prioritised (Cambodia, 2011: 68).

- International donor grants: In some countries, development partners fund specific social protection programmes. Rwanda proposes that the development of a sector-wide funding mechanism will allow development partners to contribute to the sector as a whole, rather than specific projects, ensuring that funding is aligned to government priorities. Sector-wide funding mechanisms will also enable development partners to engage over the whole sector (Rwanda, 2011: 7). In some contexts, joint pool arrangements are in place. In Uganda, as a short and medium-term financing strategy, the government jointly finances some aspects of social protection in partnership with development partners (Uganda, 2015: 41). Joint pool arrangements for certain tasks are also proposed in the Cambodian strategy as well as to finance capacity building and planning, monitoring and information and knowledge management activities for the coordination of NSPS implementation (Cambodia, 2011: 68).

- Civil society, traditional and informal sources: Often, non-state actors play a crucial role in supporting the most vulnerable in a variety of ways (Kenya, 2011: ix). The Ugandan strategy promotes traditional and informal social protection initiatives to ensure that families and communities provide support and care for vulnerable groups (e.g. widows, orphans, abandoned children, persons with severe disabilities, the chronically ill and older persons) (Uganda, 2015: 41).

- Private sector: Businesses can also play a role in improving the working environment and in promoting occupational safety and health. Contributions from businesses in the 
form of provisions for Corporate Social Responsibility (CSR) can be one source of finance (Ethiopia, 2012: 22; Uganda, 2015: 41).

\section{Communications strategy}

As noted above, few of the strategies reviewed here include detailed communication strategies.

The Kenyan strategy recognises that social protection is not a widely understood concept nationally, highlighting the need for a "comprehensive communication and influencing strategy" to raise awareness and engender ownership of the programme by relevant stakeholders and implementing partners. To do this, it aims to provide information on the concept in accessible formats and monitor the effectiveness of CIS. It recognises that implementing institutions and structures will require additional capacity related to both conceptual and operational issues. Communications materials produced will include Parliamentary reports, presentations to stakeholders, and public information. Information will be disseminated to the general population through electronic, print, social and folk media, as well as community-based communication channels, such as vernacular radio stations and theatre groups (Kenya, 2011:35).

Although the Rwandan strategy is less detailed, it sets out a similar communications strategy for social protection to be developed within the first year of NSPS implementation. This aims to build understanding on the role of social protection, inform citizens and government on the strategy's progress, and disseminate evidence on the its impact. In order to do this, a range of media will be utilised: publications, television, radio, the internet, workshops and public meetings (Rwanda, 2011: 51).

\section{Implementation tools}

States need a way to move from strategy to implementation and a number of them have created action or implementation plans (sometimes also referred to as roadmaps) to aid this process. Some countries publish these alongside their strategies (e.g. Uganda and Rwanda) and some during the implementation phase of the strategy (e.g. Bangladesh). The implementation plans reviewed here all include some form of situation analysis, implementation framework (including roles and responsibilities of key stakeholders), some description of financing arrangements (and additional funding needed), M\&E plans, as well as an overview of potential risks or challenges.

The approaches to financing differ somewhat. While Uganda and Rwanda both provide an overall costing over the 5-year implementation period, Uganda's plan is more detailed overview of the financing arrangements over the same timeframe as well as a detailed costing of each objective being implemented (Ministry of Local Government, 2011; Ministry of Gender, Labour and Social Development, 2015b). The Rwandan plan commits to developing a financing strategy within the next three months. Bangladesh's Action Plan provides an overview of social security budgeting and required additional funds, but no financing strategy as such.

Rwanda's and Bangladesh's implementation plans both also include specific gender-focused actions. Bangladesh's Plan acknowledges that men and women don't only face different risks but are also affected differently by the same risks and proposes that the National Social Security Strategy can create positive social effects (Cabinet Division and General Economics Division of Planning Commission 2016: 9). 


\section{Good practice}

This section identifies examples of good practice relevant to development and implementation of national social protections strategies, from the strategies themselves or relevant literature:

Good understanding of the local context is critical to developing a sustainable national social protection strategy. There is evidence that political, economic, social, historical and institutional factors and actors support the drive for or resistance to social protection policy uptake in, for example, Botswana (Botlhale et al., 2015) and Ghana (de-Graft Aitkins et al., 2016: 106). The development of national social protection policies must be grounded in good political economy analysis.

Management Information Systems (MISs) are integral to the design of social protection schemes; most of the strategies in this review identify the development of MISs as an important step to implementing their strategies. HelpAge International (2011) examines good practice in the design of MISs for social protection, highlighting that:

- While a fully electronic system can enable social protection schemes to run effectively, the amount of information managed determines the design and effectiveness of an MIS. Simpler social protection schemes require minimal information, resulting in MISs that are less complex and easier to manage. The main role of MISs is to enable the effective management of operations and performance monitoring. They are less reliable in providing monitoring information on recipient households, as this is only accurate at the point of capture. Therefore, information held in MISs cannot be used to evaluate the impacts of schemes on recipient families. Many schemes collect excessive amounts of information on recipients, much of little use and often inaccurate. There are alternative means of obtaining information on how recipients are responding to the programme.

- Despite the potential new information and communication technologies have for designing and deploying social protection MISs, the social protection sector in lowincome countries tends to focus on becoming computerised, rather than moving to fully integrated electronic systems. There are a range of options for moving to fully integrated systems which could be applied in low-income countries.

- MISs depend on the quality of staff who engage with the system. Capable staff are needed for data capture, data entry, repairs, system supervision and management, and MIS support services.

- Although the promotion of a Single Registry dominates debates on integrating MISs, countries usually have a number of social protection MISs. Good practice aims to achieve good integration and sharing between these.

Monitoring and evaluation are critical during initial phases of programme implementation. Drawing on experiences from four different country settings (Ghana, Kenya, Mozambique and Moldova), Attah et al (2015) outline a Conceptual Framework for building an effective M\&E system which addresses supply and demand side factors concurrently. On the supply side three dimensions need to be considered: the development of indicators and targets (based on information needs; prioritising and refining), the establishment of data sources (mix monitoring and evaluation components; build on existing data sources; minimise data collection burden), and the setting up of institutional arrangements and processes (institutional arrangements of M\&E must reflect overall institutional structure of programme; building institutional arrangements takes time). On the demand side several factors enable the use of M\&E data by intended users: 
national policy environment ('enabling' national policy; institutional culture; role of donors and civil society), implementing agency (autonomy and incentives; backing for M\&E system; culture of benchmarking performance; communication between central and decentralised levels and existence of standard service agreements) and individuals (understanding value of M\&E; fear of M\&E; capacity constraints) (see Attah et al 20015 for more detail).

Building data analysis capacity is key. While many of the national social protection strategies set out (sometimes in great detail) what types of data will be collected, how and by who, less attention is paid to analysis of this data. The Rwandan strategy stresses that it is "absolutely essential" that "capacity is established to ensure that the Government can undertake its own analytical and policy work on social protection, collaborating, as appropriate, with development partners" (Rwanda 2013: 48-49). The Cambodian strategy also highlights "analytical capacity on poverty and vulnerability and the design and adjustment of social safety net interventions in a changing socioeconomic environment" as an area in which in government staff in the Council for Agricultural and Rural Development (CARD, the agency overseeing the development and implementation of the National Social Protection Strategy) and relevant line ministries will be trained in during the initial implementation phase of the strategy (Cambodia, 2011: 61-65).

A long-term financing strategy is necessary for sustainable national social protection strategies. It is crucial to understand the overall financing needs and develop an implementation strategy that reflects sector priorities through a fully costed action plan, including different options for scaling up according to different future scenarios (e.g. economic growth) (OECD, 2017: 119120). The national social protection strategy should be complemented by a financing strategy to ensure that the new system is sustainable (ibid: 15).

\section{References}

\section{National social protection strategies and policies}

The Federal Democratic Republic of Ethiopia (2012) National Social Protection Policy of Ethiopia, Ministry of Labour and Social Affairs See: http://pheethiopia.org/resadmin/uploads/attachment-188-Ethiopia_National_Social_Protection.pdf

Government of Bangladesh Global Economics Division in Planning Commission (2015) National Social Security Strategy (NSSS) of Bangladesh See:

https://socialprotection.org/discover/publications/national-social-security-strategy-nsssbangladesh

Government of the Kingdom of Lesotho (2015) National Social Protection Strategy See: https://socialprotection.org/discover/publications/lesothos-national-social-protection-strategy

Government of Liberia (2013) National Social Protection Policy and Strategy See: http://extwprlegs1.fao.org/docs/pdf/lbr170072.pdf

Hashemite Kingdom of Jordan (2019) National Social Protection Strategy 2019-2025

Kingdom of Cambodia (2011) National Social Protection Strategy for the Poor and Vulnerable (2011 to 2015) See: http://www.cdc-

crdb.gov.kh/cdc/documents/Sector_Strategy/5_Social_Protection_Food_Security_Nutrition/Natio nal_SP_Strtegy_for_the_Poor_and_vulnerable_2011_2015_ENG.pdf 
Ministry of Gender, Children and Social Development (2011) Kenya National Social Protection Policy See: https://socialprotection.or.ke/about-sps/kenya-national-social-protection-policy

Ministry of Local Government (MINALOC) (2011) National Social Protection Strategy Republic of Rwanda. See:

http://africanchildforum.org/clr/policy\%20per\%20country/rwanda/rwanda_socialprotection_2011_ en.pdf

Ministry of Community Development, Mother and Child Health (2014) National Social Protection Policy, Republic of Zambia See: https://www.mcdsw.gov.zm/wp-

content/uploads/2019/08/NATIONAL-SOCIAL-PROTECTION-POLICY.pdf

The Republic of Uganda (2015) The National Social Protection Policy: Income Security and Dignified Lives for All See: http://socialprotection.go.ug/wp-content/uploads/2016/07/NationalSocial-Protection-Policy-uganda.pdf

\section{Revised national strategies}

Kingdom of Cambodia (2016) National Social Protection Policy Framework 2016-2025 (unofficial translation). See https://www.rcrc-resilience-southeastasia.org/wp-

content/uploads/2018/01/2017-National-Social-Protection-Policy-Framework-2016-2025-

NSPPF.pdf

\section{Implementation tools}

Cabinet Division and General Economics Division of Planning Commission (2016) Action Plan: Implementation of National Social Security Strategy (NSSS) of Bangladesh, Government of the People's Republic of Bangladesh. See: http://socialprotection.gov.bd/wp-

content/uploads/2018/04/Action-Plan-of-NSSS-complete-version-4th-Edition.pdf

Ministry of Local Government (2011) Implementation Plan for the National Social Protection Strategy (2011-2016), Republic of Rwanda See:

http://documents.worldbank.org/curated/en/305401468145757724/pdf/707740ESWOP11700of0C limate00TFESSD0.pdf

Ministry of Gender, Labour and Social Development, (2015b) Programme Plan of Interventions for Implementation of the Uganda National Social Protection Policy Fiscal Years 2015/16 2019/20, The Republic of Uganda

\section{Other}

Attah, R. et al (2015) How to move beyond the impact evaluation trap? Challenges and solutions for the setting up of comprehensive M\&E systems for Social Protection Programmes, Oxford Policy Management https://www.opml.co.uk/files/2018-05/workingpaper-mande-systemsspp.pdf?noredirect=1

Bothlhale, E. et al (2015) A Political Economy Analysis of Social Protection Programmes in Botswana, Working Paper 001, Partnership for African Social and Governance Research. See: https://www.pasgr.org/wp-content/uploads/2016/04/A-Political-Economy-Analysis-of-SocialProtection-Programmes-in-Botswana.pdf 
de-Graft Aitkens, A. et al (2016) A Political Economy of Social Protection Policy Uptake in Ghana, PASGR Working Paper 008, Partnership for African Social and Governance Research.

See: https://www.pasgr.org/wp-content/uploads/2017/02/A-Political-Economy-of-Social-

Protection-Policy-Uptake-in-Ghana_F.pdf

ESCWA (2019) Social protection reform in Arab countries, United Nations Economic and Social Commission for Western Asia See:

https://www.unescwa.org/sites/www.unescwa.org/files/publications/files/social-protection-

reforms-arab-countries-2019-english.pdf

HelpAge International (2011) Good practice in the development of management information systems for social protection, Pension Watch: Briefings on social protection in older age, Briefing 5. See: https://www.developmentpathways.co.uk/wp-content/uploads/2018/06/Good-Practice-inthe-Development-of-Management-Information-Systems-for-Social-Protection-Help-AgeInternational.pdf

Malay Mail (2019) Govt drafting National Social Protection Policy, Malay Mail, 12 December. See: https://www.malaymail.com/news/malaysia/2019/12/12/govt-drafting-national-socialprotection-policy/1818669

Ministry of Gender Labour and Social Development (ND) National Social Protection Policy, The Republic of Uganda website http://socialprotection.go.ug/national-social-protection-policy-3/

OECD (2017), Social Protection System Review of Cambodia, OECD Development Pathways, OECD Publishing, Paris. See

https://www.oecd.org/countries/cambodia/SPSR_Cambodia_ebook.pdf

Pino, A and Badini Confalonieri, A.M. (2014) National social protection policies in West Africa: A comparative analysis, International Social Security Review 67(3-4) See: https://www.socialprotection.org/gimi/RessourcePDF.action?id=49337

Said Alsayyad, A. (2017) Social Protection in Saudi Arabia, Policy in Focus, 14(3): 64-67 See https://ipcig.org/pub/eng/PIF40_Social_protection_after_the_Arab_Spring.pdf

Villar, F. (2013) The Philippine Social Protection Framework and Strategy, Paper presented at 12th National Convention on Statistics (NCS), Mandaluyong City October 1-2. See: https://www.academia.edu/24772907/THE_PHILIPPINE_SOCIAL_PROTECTION_FRAMEWOR K_AND_STRATEGY_AN_OVERVIEW

\section{Acknowledgements}

We thank the following experts who voluntarily provided suggestions for relevant literature or other advice to the author to support the preparation of this report. The content of the report does not necessarily reflect the opinions of any of the experts consulted.

- Bernie Wyler (Independent consultant)

- Dogus Simsek (School of Slavonic and East European Studies, University College London)

- Gisela Nauk (UNDP)

- Irene Selwaness (Faculty of Economics and Political Science, Egypt) 
- Karin Seyfert (Oxford Policy Management Ltd)

\section{Suggested citation}

Orrnert, A. (2020). Review of national social protection strategies. K4D Helpdesk Report.

Brighton, UK: Institute of Development Studies. DOI: 10.19088/K4D.2021.026

\section{About this report}

This report is based on 9 days of desk-based research. The K4D research helpdesk provides rapid syntheses of a selection of recent relevant literature and international expert thinking in response to specific questions relating to international development. For any enquiries, contact helpdesk@k4d.info.

K4D services are provided by a consortium of leading organisations working in international development, led by the Institute of Development Studies (IDS), with Education Development Trust, Itad, University of Leeds Nuffield Centre for International Health and Development, Liverpool School of Tropical Medicine (LSTM), University of Birmingham International Development Department (IDD) and the University of Manchester Humanitarian and Conflict Response Institute (HCRI).

This report was prepared for the UK Government's Foreign, Commonwealth and Development Office (FCDO) and its partners in support of pro-poor programmes. It is licensed for non-commercial purposes only. Except where otherwise stated, it is licensed for non-commercial purposes under the terms of the Open Government Licence v3.0. K4D cannot be held responsible for errors, omissions or any consequences arising from the use of information contained in this report. Any views and opinions expressed do not necessarily reflect those of $F C D O, K 4 D$ or any other contributing organisation.

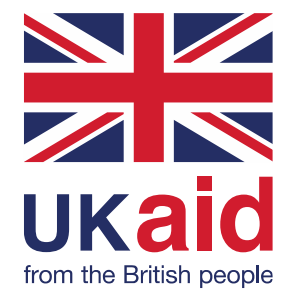

(C) Crown copyright 2020. 